\title{
Educação e memória na Casa de Dona Yayá: relato da oficina-intervenção Trafegar pelos rios do Bixiga
}

Gabriel de Andrade Fernandes ${ }^{1}$, Beatriz Bittencourt ${ }^{2}$, Maíra Martins Fróis ${ }^{3}$ e Priscila Tavares ${ }^{4}$.

As águas vão rolar...

E o nosso bloco vai navegar.

No Bixiga passa o Rio Saracura, o Itororó e o Japurá

Deixa as águas rolar!

[Trecho do samba de abertura criado pelos participantes da oficina-intervenção]

Descreve-se neste relato uma ação de cultura e extensão universitária promovida em 2013 relacionada à temática da memória urbana, da paisagem e de suas relações com o patrimônio cultural. Trata-se de uma atividade que integra o conjunto de ações promovidas pela equipe de Educação e Memória do CPC-USP e que ilustra os princípios e procedimentos por ela adotados na constituição de ações dialógicas no campo do patrimônio cultural.

\section{Educação e memória no CPC}

Ao longo do ano de 2013, a equipe de Educação e Memória do Centro de Preservação Cultural da Universidade de São Paulo (CPC-USP) buscou promover ações públicas de educação e cultura que propiciassem o encontro entre públicos, saberes e perspectivas de mundo as mais heterogêneas possíveis: tinha-se como horizonte a constituição de uma práxis sobre o patrimônio cultural que fosse ela própria demonstrativa e enunciadora (e, portanto, em certo sentido didática) da condição inerentemente conflitiva e tensa que caracteriza o próprio patrimônio. Se o patrimônio cultural, como sugere o professor Ulpiano Meneses (2009), configura-se como um campo de disputa de valores, de significações e de representações - e se expressa por meio de um conjunto de objetos e práticas cujos valores patrimoniais não lhes são imanentes, mas sempre atribuídos socialmente —, então nos parece 
que qualquer ação patrimonial que se pretenda educativa (e, portanto, dialógica) deve ela própria estar aberta ao confronto de ideias, representações e significações do que seja patrimônio. As atividades promovidas pela equipe voltadas ao público externo procuraram explicitar, portanto, esta concepção ampliada de patrimônio cultural, na qual a ação educativa não se caracteriza pela transmissão de valores culturais congelados e heteronômicos, mas pela efetiva constituição de um espaço de debate e de ação, no qual o patrimônio cultural se expressa pela manifestação cultural partilhada dos sujeitos que dele tomam parte.

Neste sentido, cabe destacar três das várias ações desenvolvidas pela equipe neste ano - das quais uma será objeto de relato mais detalhado - que, atuando com públicos distintos, buscaram problematizar dialogicamente tal conjunto de questões. A primeira delas foi a Oficina de Stop-motion promovida com os estudantes do 6은 ano da Escola Estadual Maria Augusta Saraiva. A segunda constitui-se do conjunto de Encontros de formação (ocorridos em junho de 2013) e de Jornadas de patrimônio e educação (ocorridas em outubro), voltadas a profissionais ligados à educação formal e não formal (e ao público geral interessado). A terceira foi a oficina-intervenção Trafegar pelos Rios do Bixiga, ocorrida em outubro. A Oficina de Stop-motion e a oficina-intervenção foram também objeto da parceria do CPC com o Coletivo Mapa Xilográfico, formado por artistas e educadores que promovem reflexões sobre o espaço urbano, as práticas cotidianas na cidade e seu processo de construção e destruição por meio de ações estéticas de forte caráter político.

A Oficina de Stop-motion reuniu cerca de 30 estudantes de uma turma de $6^{\circ}$ ano da Escola Estadual Maria Augusta Saraiva. Ao longo de cinco encontros reunindo estudantes, a equipe de Educação e Memória e os arte-educadores do Coletivo Mapa Xilográfico, foram produzidos cinco vídeos em curta-metragem relacionados ao patrimônio cultural vivido cotidianamente pelos sujeitos que os desenvolveram (no caso, crianças e adolescentes com cerca de 10 anos de idade que moram e estudam no bairro do Bixiga). Os estudantes foram divididos em equipes e cada uma delas orientou e conduziu a produção de seus vídeos da maneira que melhor thes parecia, assistidos pela equipe de Educação e Memória e com a coordenação do Coletivo Mapa Xilográfico. O resultado foi um rico conjunto de representações e narrativas a respeito do cotidiano de tais meninos e meninas: aos elementos vividos 
no dia-a-dia foram acrescidas marcas de fantasia e de ficção que possibilitaram uma discussão coletiva sobre os problemas e as perspectivas sobre o bairro em que vivem. Os vídeos, editados pelo Coletivo Mapa Xilográfico, foram exibidos na Casa de Dona Yayá no dia 3 de julho, com a participação de pais e amigos dos estudantes.

Os Encontros e Jornadas de Patrimônio e Educação, coordenados pela arquiteta e especialista em patrimônio cultural Samira Chahin, reuniram profissionais da educação atuantes nos mais variados espaços (escolas, museus, instituições culturais, organizações não governamentais etc.) dispostos a discutir e trocar experiências relacionadas à interface entre os universos da educação e do patrimônio cultural. Em junho ocorreram os encontros, no formato de um conjunto de oficinas ministradas por Samira Chahin, nos quais se articularam discussões em roda com saídas experimentais pela cidade formatadas a partir de temas geradores identificados entre os participantes. Em outubro ocorreram as jornadas, para as quais o CPC convidou educadores atuantes em diferentes partes do país para se juntarem à discussão em curso.

Finalmente, a oficina-intervenção Trafegar pelos rios do Bixiga, conduzida pelo Coletivo Mapa Xilográfico com o apoio da equipe de Educação e Memória, caracterizou-se pela construção coletiva de uma intervenção urbana que evidenciasse, celebrasse e problematizasse a relação entre paisagem, memória, cidade e vida. Os participantes tinham as origens mais variadas, bem como pertenciam a faixas etárias, camadas sociais e graus de escolaridade diversos. Enquanto as primeiras duas ações configuraram-se como atividades formatadas para públicos bastante específicos, esta última foi bastante ampla e heterogênea, pelo que será a seguir objeto de descrição mais aprofundada a seguir. Note-se, contudo, que este conjunto de ações promovido pela equipe nutre-se de um objetivo comum: o de estabelecer um espaço comum de discussão do que seja o patrimônio cultural dos sujeitos com quem estabelecemos um nível qualquer de interlocução, de modo a explicitar conflitos, tensões e partilhas entre tais manifestações culturais, propiciando, portanto, um espaço político (e, portanto, profundamente educativo) de construção do patrimônio cultural. 


\section{Navegar pelo asfalto}

A oficina-intervenção Trafegar pelos rios do Bixiga foi proposta pelos integrantes do Coletivo Mapa Xilográfico como uma ação decorrente das atividades promovidas em junho com a Escola Estadual Maria Augusta Saraiva. Para além da realização de um trabalho com um público restrito, ficou o desejo, tanto da equipe de Educação e Memória do CPC como do Coletivo, em de promover uma ação criativa e sensível no espaço público, na qual fosse possível construir memórias urbanas a partir de seus vestígios materiais e de seus protagonistas, articulando representações, imagens e recordações construídas pelos seus sujeitos.

Trata-se de uma ação de cultura e extensão universitária que ocorre em campo e é construída horizontalmente com seus participantes, não sendo em nenhum momento imposta verticalmente. Mais que isto: trata-se de uma ação que é ao mesmo tempo oficina e evento público, reunindo tanto um público específico que participou de sua construção quanto um público ampliado, heterogêneo e espontâneo, que se juntou a ela a cada uma das saídas pela cidade que a ação promoveu.

Se, de um lado, a oficina permite a difusão de um conjunto de informações patrimoniais que em princípio não são de amplo conhecimento - no caso, o da estrutura hídrica urbana que está escondida sob o asfalto da cidade - , de outro, ela só se efetiva na medida em que permite a construção de múltiplas significações dos suportes de memória com o qual trabalhamos, em um processo plural de atribuição de valores patrimoniais. Não se trata aqui da celebração de bens patrimoniais oficializados como tal, mas da celebração sensível da cidade tal como ela se encontra: como uma imensa colcha de retalhos na qual os diferentes sentidos possuem igual relevância.

A oficina promoveu, portanto, um conjunto de rituais poéticos de identificação simbólica e de celebração criativa dos rios que correm no território do bairro do Bixiga, onde está localizada a Casa de Dona Yayá, os quais se encontram atualmente invisíveis, já que estão canalizados e enterrados. Ela sugeriu a seus participantes (tanto aqueles que inscreveram previamente quanto aqueles que foram capturadas por ela à medida que seus cortejos avançavam pelas ruas do bairro) que 
"navegassem" em pleno asfalto, contrariando, portanto, a lógica usual de apropriação da cidade pelos seus moradores: mais do que deslocar-se, tratava-se de promover o movimento ativo, consciente e alegre; mais do que ver, olhar para os vestígios e confrontá-los com as memórias e representações que foram construídas ao longo da oficina.

Pretendia-se desde o início promover uma ação nestes rios invisíveis que fosse alegre, poética, sensível. A formatação final das ações, porém, ficou em aberto até que a oficina começasse, de modo a receber as contribuições dos participantes e a torná-las uma proposta comum. Partiu-se, entretanto, de uma proposta-provocação: a constituição de um "barquinho" urbano, movido por rodas e por memórias, que ao mesmo tempo propiciasse a navegação pelas ruas do Bixiga para quem nele quisesse adentrar como a indicação da existência de um rio sob suas rodas.

\subsection{Rios invisíveis do Bixiga}

Embora não possua definição legal, o bairro do Bixiga costuma ser entendido como um território que se confunde com parte dos distritos da Bela Vista e da Liberdade e sobre o qual são construídas as mais variadas representações: "bairro italiano", "bairro negro", "bairro nordestino", "periferia do centro", entre outras (como revelou, inclusive, o projeto Bixiga em Artes e Ofícios, outro conjunto de ações promovido pelo CPC nos últimos anos). Independente disso costuma haver um consenso de que o Bixiga exista em meio a um conjunto de ruas e quadras posicionadas em uma mancha de conformação variável que costuma apresentar por limites vias como as avenidas 9 de Julho e 23 de Maio. Trata-se, portanto, de um território identificado com certo imaginário, o qual é construído a partir de uma geografia de morros e vales, escadarias e ladeiras, altos e baixos. Nesta topografia encontra-se uma rica rede fluvial que foi gradualmente escondida à medida que os processos de urbanização avançavam.

Três são os rios particularmente relevantes neste território, objetos de intervenção em nossa oficina: tratam-se dos córregos Saracura, Itororó e Japurá (também conhecido como Ribeirão Bixiga). Tais corpos fluviais encontram-se hoje sob importantes vias do bairro: o córrego Saracura corre em parte sob o leito da Avenida 
9 de Julho, desaguando no Rio Rio Anhangabaú. Parte do córrego Itororó está canalizada sob a Avenida 23 de Maio e o Japurá encontra-se em parte sob a rua de mesmo nome, este desaguando naquele (o qual, por sua vez, transforma-se no Rio Anhangabaú quando se encontra com o Rio Saracura). Os momentos da canalização e posterior tamponamento de cada um dos córregos são diversos, mas é ainda possível encontrar espalhados pelo bairro do Bixiga pessoas que compartilham recordações e constroem memórias da existência visível de tais rios, bem como sujeitos que dialogam cotidianamente hoje com as manifestações visíveis de suas existências silenciadas: desde pessoas que se acostumaram a usar as águas de uma das nascentes do rio Rio Saracura até os relatos dos desdobramentos de enchentes causadas pela vazão excessiva dos rios que as estruturas canalizadas eventualmente não suportam.

Trata-se, portanto, de uma cultura material pouco explícita, mas profundamente relevante para a vida de um grupo variado de sujeitos - os quais, por sua vez, constituem suas vidas em diálogo com este imaginário e com estas referências, produzindo, portanto, manifestações culturais fortemente associadas a elas. Lidamos, assim, com uma espécie de patrimônio cultural bastante complexa: são referências culturais e suportes de memória a que se articulam a tensão e a imprevisibilidade da vida urbana, reunindo em uma mesma existência conflito e celebração. A memória dos rios, seus vestígios e o conjunto de existências materiais que continuamente se constroem, destroem e se reconstroem sobre eles constitui um riquíssimo conjunto de extratos e camadas de memória e de cultura com a qual procuramos dialogar ao longo de nossas ações.

O estudo dos rios de São Paulo (e particularmente dos seus rios invisíveis) não é, aliás, algo inédito nem recente. Trata-se de uma problemática de pesquisa já bastante amadurecida: cabe destacar, por exemplo, os esforços de um conjunto de pesquisadores liderados por Vladimir Bartalini, na Faculdade de Arquitetura e Urbanismo da Universidade de São Paulo (FAU-USP), ou os trabalhos de Odette Seabra, do Departamento de Geografia da USP. No entanto, parece-nos que ainda se trata de uma temática pouco abordada pelas ações de cultura e extensão, o que causa certo espanto, na medida em que se trata de uma situação que potencialmente articula espaço, memória, cotidiano e paisagem, e propicia a 
realização de ações culturais as mais variadas. É nesta perspectiva que procuramos orientar nossas ações.

\section{Estrutura da oficina-intervenção}

A oficina-intervenção foi dividida em três momentos: derivas pela cidade (realizadas pela equipe e pelo Coletivo); oficinas preparatórias (em dois encontros com 0 público); intervenção urbana (em três encontros com o público). Seguem breves descrições de cada uma das etapas. Ressalte-se, porém, que elas compõem um material sobre o qual ainda produziremos reflexões futuras mais aprofundadas.

\subsection{Derivas pelo Bixiga}

Ao longo do mês de setembro os membros do Coletivo Mapa Xilográfico e da equipe de Educação e Memória do CPC percorreram o bairro do Bixiga em busca de histórias, recordações e experiências ligadas a este território e aos seus rios. Apesar de serem percursos baseados em bibliografia já existente sobre tal hidrografia, havia também um desejo de enfrentar a surpresa e a contingência que o cotidiano urbano oferece. Neste sentido, o contato com os moradores e frequentadores do bairro se deu à medida que novos interlocutores eram encontrados, muitas vezes ao acaso.

Estas andanças permitiram estabelecer, portanto, ligações com alguns dos personagens do bairro: revelaram-se histórias de relação com os rios, lembranças tristes e alegres, de enchentes e de brincadeiras. Tais interlocutores foram convidados a participarem das intervenções que ocorreriam no mês seguinte, bem como foram também solicitados a compartilhar suas memórias com o público externo que viria a se juntar à oficina.

\subsection{Oficinas preparatórias}

Formatadas para um público de cerca de 20 pessoas, as atividades ocorreram ao longo de dois domingos, nos dias 29 de setembro e 6 de outubro - devido ao grande número de interessados, porém, optamos por ampliar para 30 o número de vagas. Essas oficinas foram pensadas como um processo de trabalho coletivo 
voltado à preparação das intervenções urbanas que ocorreriam nos domingos seguintes, dias 13, 20 e 27 de outubro. Neste sentido, os participantes foram estimulados a refletirem sobre a relação entre a cidade e seus rios, entre o cotidiano e as águas, entre os sujeitos e as paisagens que eles constroem em no seu dia-adia.

No primeiro encontro o Coletivo Mapa Xilográfico apresentou seu trabalho poético na cidade e propôs alguns problemas a serem discutidos: por quem e para quem a cidade é produzida? Por quem e para quem vestígios de memória são apagados e outros construídos? Que relação estabelecemos com o espaço público ao nos deslocarmos? O que apagamos e o que construímos em nossa ação urbana cotidiana? Como dispositivos disparadores de provocações, foram exibidos e discutidos alguns filmes sobre São Paulo: À deriva (produção do próprio Mapa Xilográfico) e Entre rios (famoso documentário sobre a relação entre a urbanização paulistana e seus rios).

No segundo encontro os participantes dividiram-se em grupos de trabalho: alguns construíram coletivamente os sambas que seriam cantados nas intervenções dos próximos domingos; outros produziram xilogravuras que seriam distribuídas pelas ruas, bem como filipetas informativas da intervenção e dos rios; outros trabalharam na produção de estêncile, ainda outros percorreram o bairro em busca de materiais a serem incorporados ao barquinho que estava em construção (materiais que se revelaram como o refugo da cidade, como a matéria descartada pelos viventes, mas repleta de extratos de histórias e representações). Tratava-se, afinal, de promover o combustível que moveria o barquinho que estávamos construindo para os domingos seguintes.

Além disso, como ritual que marcou o início dos trabalhos, todos participaram da gravação de um estandarte para o barco: os sulcos e restos de uma árvore que fora recém-cortada no Bixiga foram usados como matriz para produção de uma xilogravura.

\subsection{Intervenções urbanas}


Finalmente, ao longo dose três domingos (13, 20 e 27 de outubro), deram-se as saídas pela cidade: cortejos iniciados pelos participantes da oficina aos quais se somavam as pessoas que transitavam pelas ruas, que descansavam em suas casas ou que celebravam nos bares que se encontravam pelos caminhos. Produziu-se, de fato, uma festa urbana, uma ocupação alegre e sensível do espaço público, cativante e contagiosa. $O$ material produzido pelos grupos de trabalho que se organizaram nos domingos anteriores foi sendo distribuído pelas ruas à medida que as pessoas se interessavam, e se somava à procissão em busca de cada um dos rios. As crianças do bairro, particularmente, encantaram-se com o barquinho navegando pelo asfalto: corriam para navegar dentro dele.

Os sambas compostos no dia 6 de outubro eram entusiasticamente cantados em cada uma das intervenções, dedicadas a cada um dos rios do Bixiga visitados: Rio Japurá, no dia 13, rio Rio Saracura, no dia 20 e rio Rio Itororó, no dia 27.

\section{Conclusão}

Esta experiência constitui demonstração de como é possível (e necessário) promover ações de educação e cultura em campo, no espaço urbano, a partir de uma perspectiva de construção não hierarquizada de conhecimento, de modo horizontal, alegre e sensível, incorporando o risco e a contingência que são próprios do que nos acontece. Além disso, ela revela a necessidade de uma ocupação mais sensível da cidade: revela a necessidade de estabelecer diálogos sinceros entre diferentes sujeitos e diferentes saberes, de estabelecer pontes entre memórias e representações dispersas pelo cotidiano urbano e distantes da história oficializada e institucionalizada de bairros e de lugares. Finalmente, sugere a possibilidade da utopia: outra forma de ocupar a cidade, de deslocar-se nela e de viver o urbano. Mais do que revelar rios invisíveis, esta oficina-intervenção permitiu que tais rios fossem inventados: não há invenção sem diálogo, sem partilha e sem desejo.

\section{REFERÊNCIAS}

À DERIVA. São Paulo: Coletivo Mapa Xilográfico, 2013. Vídeo em média-metragem. Disponível em: <http://vimeo.com/51460632>. Acesso o em: nov. 2013.

Bartalini, Vladimir. A trama capilar das águas na visão cotidiana da paisagem. In: Revista da USP, n. 70, p. 88- 
97, jun.-ago. 2006.

COLETIVO MAPA XILOGRÁFICO. (À) deriva metrópole São Paulo. São Paulo, mimeo 2010. Disponível em: <http://mapaxiloaderiva.blogspot.com.br/2013/01/revista-deriva-metropole-sao-paulo.html>. Acesso em: nov. 2013.

ENTRE rios. Vídeo em média-metragem. Disponível em: <http://vimeo.com/14770270>. Visitado Acesso em: nov. 2013.

Meneses, Ulpiano. O campo do patrimônio cultural: uma revisão de premissas. Anais do I Fórum Nacional do

Patrimônio Cultural. Ouro Preto: Iphan, 2009. Disponível em: <http://www.iphan.gov.br/baixaFcdAnexo.do?id=3306>. Acesso em: nov. 2013.

\section{Notas}

(1) Coordenado da equipe de Educação e Memória do Centro de Preservação Cultural da Universidade de São Paulo (CPC-USP). É formado em Arquitetura e Urbanismo pela Faculdade de Arquitetura e Urbanismo da Universidade de São Paulo (FAU-USP). E-mail: gaf.arq@usp.br

(2) Estagiária da equipe de Educação e Memória do CPC-USP. Graduanda em Artes Cênicas na Universidade de São Paulo (ECA-USP).

(3) Estagiária da equipe de Educação e Memória do CPC-USP. Graduanda em Artes Cênicas na Universidade de São Paulo (ECA-USP).

(4) Estagiária da equipe de Educação e Memória do CPC-USP. Bacharel em Comunicação das Artes do Corpo da Pontifícia Universidade Católica (PUC-SP) e graduanda em Pedagogia na Universidade de São Paulo (FE-USP).

\section{Referências}

BARTALINI, Vladimir. A trama capilar das águas na visão cotidiana da paisagem. Revista da USP, n. 70, pp. 88-97, jun.-ago. 2006.

Coletivo Mapa Xilográfico. À deriva. Vídeo em média-metragem. Disponível em: <http://vimeo.com/51460632>. Acesso em: nov. 2013. 
(À) deriva metrópole São Paulo. São Paulo. Disponível em: <http://mapaxiloaderiva.blogspot.com.br/2013/01/revista-deriva-metropole-sao-paulo.html>. Acesso em: nov. 2013.

ENTRE rios. Vídeo em média-metragem. Disponível em: <http://vimeo.com/14770270>. Acesso em: nov. 2013.

MENESES, Ulpiano. O campo do patrimônio cultural: uma revisão de premissas. Anais do I Fórum Nacional do Patrimônio Cultural. Ouro Preto: Iphan, 2009. Disponível em: <http://www.iphan.gov.br/baixaFcdAnexo.do?id=3306>. Acesso em: nov. 2013. 